Revista de Dialectología y Tradiciones Populares, vol. LXX, n. ${ }^{\circ}$ 2, pp. 291-297, julio-diciembre 2015, ISSN: 0034-7981, eISSN: 1988-8457, doi: $10.3989 /$ rdtp.2015.02.001.03

\title{
Los problemas de las fronteras humanitarias ${ }^{2}$
}

\author{
The Problems with Humanitarian Borders
}

\author{
Miriam Ticktin \\ Codirectora del Centro Zolberg para la Migración Global \\ New School for Social Research
}

\section{RESUMEN}

Este texto plantea un análisis crítico del papel de los discursos y prácticas humanitaristas en nuestra concepción de la migración y en las políticas públicas desarrolladas en relación a la movilidad poblacional a través de las fronteras internacionales. Se parte de la premisa de que el humanitarismo, aunque fuera bien intencionado, puede tener efectos perniciosos sobre la situación que se vive en las fronteras, especialmente si acaba por sustituir a la justicia y a los derechos que tienen los emigrantes. Para estudiar esta paradoja, el texto analiza, sucesivamente, varios problemas asociados a la acción humanitaria: el problema con la inocencia - la victimización de refugiados les hace objeto de compasión humanitaria-; el problema con la emergencia — con dinámicas de 'acción inmediata' que impiden la comprensión contextualizada e histórica de los fenómenos-; y, finalmente, el problema de la compasión —el humanitarismo se asocia más con sentimientos que con derechos. El análisis de estas tres categorías claves en las retóricas humanitaristas tanto en Europa como en Estados Unidos permite, a fin de cuentas, un sano escepticismo frente a nuevas formas de legitimación de la exclusión. La autora explora también estrategias políticas y discursivas alternativas que sientan las bases de nuevos imaginarios más allá de las fronteras y de humanitarismos que reproducen la desigualdad global eludiendo enfrentar la justicia como horizonte de acción.

Palabras clave: Humanitarismo; Emigración; Fronteras; Justicia; Compasión; Emergencia.

\section{SUMMARY}

This text engages a critical analysis of humanitarian discourses and practices regarding our understanding of migration and the public policies developed in relation to the population movementsacross international borders. It is based on the premise that humanitarianism, even if well intentioned, can have pernicious effects if, eventually, it ends up replacing justice and migrants' rights. To explore this paradox, the paper sequentially analyzes various problems associated with humanitarian

\footnotetext{
${ }^{2}$ Este artículo se escribió antes del verano de 2015 (nota de la coord.). Traducido de la versión inglesa por Liliana Suárez Navaz.
} 
aid: the problem of innocence - the understanding of refugees as victims calls for humanitarian compassion-; the problem with emergency — rapid response" operations inhibit the contextualized and historical understanding of the root causes of the problems-; and, finally, the problem of compassion - humanitarianism privilegessentiments over rights. The study of these three key features of humanitarianism in Europe and the USA fosters a healthy skepticism of the emerging forms of the legitimation of exclusion. The article also explores alternative political and discursive strategies which allow for new imaginaries to confront migratory processes beyond borders and humanitarianism, breaking up their dynamic of reproduction of social inequalities and placing justice in the horizon of action.

Key words: Humanitarianism; Migration; Borders; Justice; Compassion; Emergency.

El discurso humanitario ha estado muy presente en los debates políticos y mediáticos sobre los inmigrantes indocumentados que cruzan las fronteras hacia Europa o hacia Norteamérica. Los menores no acompañados que llegaron a los Estados Unidos el pasado verano de 2014 fueron calificados como "crisis humanitaria", mientras que el momento crítico en el Mediterráneo llegó en abril de 2015, cuando al menos 5 barcos se hundieron y casi 1.200 personas se ahogaron en su ruta a Europa.

En respuesta al ahogamiento de otras 700 personas en su ruta desde Libia a Lampedusa, la alta representante de la Unión para Asuntos Exteriores y Política de Seguridad, Federica Mogherini dijo “La Unión Europea se creó con la idea de proteger los derechos humanos, la dignidad y la vida humanas. Tenemos que ser coherentes con esa idea" ${ }^{3}$. La Comisión Europea manifestó que quería adoptar "medidas urgentes para prevenir las tragedias humanas y lidiar con las emergencias". Propuso un plan para reducir la pérdida de vidas a través de estrategias conjuntas de búsqueda y rescate. De hecho hay ya una multitud de ONGs que trabajan en los distintos puntos de entrada a Europa, como Ceuta y Melilla en España o Lampedusa en Italia, desde las grandes y conocidas como el Comité Internacional de la Cruz Roja o Médicos del Mundo hasta muchas otras organizaciones locales.

En Estados Unidos pasa algo semejante. Cuando la llegada de los menores no acompañados se denominó "crisis humanitaria" y "situación humanitaria urgente" por parte de los políticos, el presidente Obama respondió inicialmente que además de crear las condiciones para que los niños hondureños pudieran solicitar asilo desde su país, consideraría la aplicación de un "visado humanitario" para estos niños, lo que implica una admisión temporal debido a una emergencia imperiosa. El humanitarismo significaba compasión para los niños que huían de una violencia inimaginable. De hecho, a Obama le criticaron tanto republicanos como oponentes a la inmigración por usar un discurso blando, que según ellos fomentaba la apertura de las compuertas. Pero el humanitarismo no es en absoluto blando. De hecho, puede llegar a herir a los que pretende ayudar. Si queremos cambiar la situación de las fronteras en Europa y Estados Unidos, necesitamos otro lenguaje: el de la justicia.

Hay varias razones por las cuales el humanitarismo no es suficientemente bueno, e incluso puede ser destructivo.

\footnotetext{
${ }^{3}$ http://www.washingtontimes.com/news/2015/apr/20/migrants-drown-in-mediterranean-aseurope-refugee/?page $=$ all
} 


\section{EL PROBLEMA CON LA INOCENCIA}

Primero, el humanitarismo crea una distinción entre inocente y culpable, sin dejar espacio a las experiencias de la vida. La víctima típica del humanitarismo no tiene responsabilidad por su sufrimiento. Su inocencia es lo que les cualifica para la compasión humanitaria. Como inocentes, son puros, sin artimañas o intenciones ocultas: lejos de la política y de la culpa de su desgracia. Aún así, ¿quienes son estas víctimas perfectas?

Los niños son la cara más común del humanitarismo: se representan como las víctimas inocentes del hambre, la guerra o los desastres naturales. Sólo tenemos que mirar las imágenes de las páginas web de organizaciones como el Comité Internacional de Rescate (IRC, en su acrónimo inglés), u Oxfam ${ }^{4}$. Pero, curiosamente, a los niños migrantes que estaban en el corazón mismo de aquella crisis humanitaria no se les reconoció el estatus de víctimas, merecedoras de la ayuda humanitaria. ¿Por qué? Parecían haberse contaminado por la asociación con los bandas y la violencia del tráfico de drogas del que huían; y por otros inmigrantes indocumentados, criminalizados por haber cruzado la fronteras para buscar una vida mejor o para reunirse con sus familias. La mezcla de centros de detención con prisiones — que cada vez más en Estados Unidos pertenecen y son gestionadas por las mismas empresas, como GEO-, es a la vez la causa y la manifestación de esta criminalización. Y ahora, ¿cuáles de estos niños pasarán el test de inocencia? ¿Quiénes cualificarán para ese visado humanitario, cuando la inocencia es lo que se requiere para obtenerlo? Los viajes hacia el norte que muchos han realizado, a menudo llenos de horribles episodios de violencia y explotación, harían perder a cualquiera esa inocencia — como si la inocencia fuera algo que uno pudiera poseer, cuando sin embargo exige un tipo de libertad del deseo, la voluntad o la agencia. Si el humanitarismo fuera el discurso que usáramos para contrarrestar políticas de cierre de fronteras y anti-inmigrantes, entonces a la mayoría de los migrantes, incluidos los niños, se les enviaría la los centros de detención o se les deportaría sin respeto a proceso legal instituido.

Un énfasis similar en la inocencia aparece en el caso Europeo. Por ejemplo, el presidente Giorgio Napolitano definió los ahogamientos frente a las costas de Lampedusa en 2013 como una "masacre de inocentes". Esto evita la pregunta de quién cometió la "masacre"; esto es, el énfasis en la inocencia y la vulnerabilidad de inmediato invoca un espacio simultáneo - y criminalización de- la culpa. En este sentido, el humanitarismo es acompañado inevitablemente por prácticas de vigilancia policial; la compasión llega acompañada de represión (Fassin 2005; Ticktin 2005). Aquí son los traficantes los que han sido designados como culpables. Pero estos "traficantes" son a menudo miembros de la propia familia, amigos o parte de las comunidades migrantes, gente que está en situaciones similares a los propios migrantes. Además se da el caso de que los propios migrantes suelen pedir ayuda para cruzar. No se trata pues de una situación sin claroscuros, como si los inocentes hubieran sido atrapados por los culpables. De hecho, ahora es del todo imposible llegar al norte global para solicitar asilo sin la ayuda de estos traficantes (Hathaway 2008). Y esto es un efecto directo de los varios aparatos de seguridad militarizados en la frontera.

\footnotetext{
${ }^{4}$ Ver http://www.rescue.org/ y https://www.oxfam.org/

5 http://www.theguardian.com/world/2013/oct/03/lampedusa-boat-tragedy-italy-migrants
} 
No está provocado por una confabulación de los traficantes. Este énfasis en los traficantes, más que en ayudar a los inocentes, potencia la criminalización y securitización de las fronteras, lo cual a su vez provoca más muertes.

De forma similar tanto los medios como los funcionarios públicos europeos han insistido desde abril en la diferencia entre "refugiados" y "inmigrantes económicos ilegales". Mientras que el asilo es una categoría legal que queremos proteger, la forma en que se está usando aquí es más moral que legal, es una distinción que intenta de hecho separar los inocentes de los culpables, los que son merecedores de ese humanitarismo de los que no. Los refugiados "reales" son vistos como inocentes - huyendo de amenazas de persecución reales y bien fundadas. Como decía la antropóloga Liisa Malkki, los refugiados, especialmente los refugiados africanos, son representados como "un 'mar' o una 'difusa humanidad'". Como un "espectáculo de 'humanidad desnuda', 'cruda'" (1996). Se les concibe como pasivos, necesitados de salvación: ésta es la imagen clásica de la inocencia. Los migrantes económicos son percibidos, en contraste a los refugiados, como taimados embusteros que intentan aprovecharse de los servicios públicos y otros beneficios del estado de bienestar europeo, de forma que debilitan no sólo la seguridad, sino los propios valores europeos. En otras palabras, el humanitarismo requiere de sufrientes inocentes representados en la pasividad de su sufrimiento, no en la acción que toman para contrarrestarlo y escapar de él (Boltanski 1999).

El énfasis en ayudar y salvar refugiados es un intento de parecer generoso y humano, mientras que limitamos su número a unas pocas excepciones. Como dijo la filósofa Hannah Arendt, "el asilo es una categoría siempre se pensó para casos excepcionales, nunca para las masas" (1951: 291). De hecho, y sólo como un ejemplo, España dio asilo en 2014 a un total de 15 personas $^{6}$. Como tal, el humanitarismo puede servir como un pretexto para quitar derechos a la mayoría en nombre de la minoría. La inocencia no debe ser un criterio que separe los que viven de los que mueren, ni como viven y mueren. En este sentido, humanitarismo - más que protección de la humanidad como un todo- establece jerarquías de humanidad (Fassin 2010). Algunos somos más humanos que otros.

\section{EL PROBLEMA CON LA EMERGENCIA}

Segundo, el humanitarismo sólo se ocupa del presente: tenemos "crisis" humanitarias o "emergencias" que requieren acción inmediata. Con esta perspectiva temporal no hay forma de entender los fenómenos en su contexto histórico más amplio. No hay tiempo de pensar en el pasado ni de planificar el futuro. El humanitarismo crea fenómenos aparentemente repentinos e impredecibles. Tales situaciones existen, sin ninguna duda: el reciente terremoto en Nepal, el huracán "Sandy" en los Estados Unidos en 2012, el terremoto en Haití en 2010, o el tsunami en el Océano Índico en 2004. Todos estos fenómenos encajan a la perfección con la definición de "crisis humanitaria". Pero hablar de cualquier situación como una emergencia humanitaria crea la impresión de que fuera una excepción a un mundo ordenado y pacífico más allá de estos fenómenos. No hay espacio para comprender la historias que hay detrás, las

\footnotetext{
${ }^{6}$ http://ec.europa.eu/eurostat/statistics-explained/index.php/File:Final_decisions_on_(nonEU)_asylum_applications,_2014_(number,_rounded_figures)_YB15_IV.png
} 
causas que condujeron o configuraron este fenómeno y este momento específico. Aumentó significativamente el número de niños que cruzaba la frontera de Estados Unidos en 2014, pero sus viajes no eran impredecibles ni repentinos. Estos menores no acompañados habían llegado al menos desde 2009 en grandes números, huyendo de la creciente violencia. Aunque el número que alarmó a la prensa en 2014 fue 52.000 o 57.000 menores, en el 2013 ya había más de 25.000, y en el 2012 unos 13.000.

Los inmigrantes llevan ya muchos años cruzando - y muriendo- desde el norte de África a Europa. Antes de que la Unión Europea se formara y se exigieran visas, la gente iba y venia sin fanfarria, según el mercado laboral estacional lo precisara. Pero después de que los acuerdos de Schengen se firmaran y estos flujos se ilegalizaran, se convirtió en una actividad más peligrosa. Las primeras muertes en el estrecho de Gibraltar datan de la década de los noventa. Las vallas en Ceuta y Melilla existen desde mediados de los ochenta pero es en 2005, tras los denominados "asaltos a las vallas", cuando una tercera valla se construye para detener los flujos irregulares de inmigrantes. Pero sabemos también que el cruce y las numerosas muertes en el mar tienen una historia cuando analizamos el desarrollo de Frontex, la Agencia Europea para la Gestión de la Cooperación Operativa en las Fronteras. ¿Cómo hubiera sido posible el desarrollo de toda su tecnología —incluyendo sensores, cámaras, cables, drones, y cables-, si se hubiera tratado de un suceso repentino, un incidente espontáneo? Y aún más: desde los años noventa ha habido un esfuerzo por parte de la UE en coordinación con ACNUR para entrenar a los países de tránsito como Marruecos en las prácticas de asilo — de esta manera subcontratando y externalizando el asilo- para que actúen como los policías de Europa y bloqueen el paso de los subsaharianos. Esto también contradice la idea de emergencia.

Para actuar sobre la cuestión necesitamos por tanto ir más allá del alcance de la emergencia: mirar a su pasado — su historia y sus causas- y pensar sobre como podemos forjar un futuro diferente.

Por ejemplo, la guerra contras las drogas $-\mathrm{y}$ las insaciables peticiones desde los Estados Unidos - la creciente desigualdad entre ricos y pobres que está provocando esta violencia, y cambiar ambas, sólo puede hacerse con nuevas estrategias. De forma similar, el "hambre" que lleva a los migrantes desde África a Europa está configurado por las historias de programas de ajuste estructural entreveradas con las historias coloniales. Y tanto las muertes en la frontera México-Americana como en el Mediterráneo están configuradas por la enormemente lucrativa industria de la migración —un ejemplo excelente del funcionamiento del capitalismo global-, y por los beneficios de las empresas transnacionales inversoras en tecnologías de vigilancia, detención y prisión. En el mejor de los casos es ingenuo sugerir que el cruce de fronteras vaya a ser detenido por las vallas, o los ahogamientos por los actores humanitarios.

\section{EL PROBLEMA DE LA COMPASIÓN}

Tercero, el humanitarismo se asocia más con sentimientos que con derechos; tiene que ver con compasión, no con titularidad de derechos. Las excepciones humanitarias son precisamente eso: excepciones a las leyes. Y normalmente se hacen en base a la emoción. Cuando se habla de los migrantes como víctimas humanitarias, les sacamos del alcance de la ley, donde tienen derecho a ser libres de la violencia. ¿Por 
qué echamos mano a excepciones, o a la caridad o benevolencia, cuando Europa y los Estados Unidos se reivindican como seguidores de la ley y practicantes ejemplares de un buen gobierno? Sólo como un ejemplo, mientras se denomina a sí mismo humanitario, el gobierno de la Casa Blanca sugería a la vez que quería quitar a los niños indocumentados los derechos que les asistían bajo el Acto de Reutorización William Wilberforce de protección a las víctimas de tráfico, que convirtió en ilegal las deportaciones inmediatas. Mientras que la gente comenzaba a reivindicar "derechos humanitarios", refiriéndose al derecho al agua, alimento y alojamiento (Feldman 2011), de hecho no hay obligación legal aún de dar ayuda, rescate, o cuidado. Por el contrario, dependemos de sensibilidades individuales, que a su vez están marcadas por ideas de quién es merecedor de compasión en términos de raza y género, y que además crece y mengua y tiene riesgos de saturación o "fatiga de compasión". Además, la compasión elige sólo a unos pocos individuos excepcionales y excluye al resto. De hecho, por su propia definición, la compasión no puede generalizarse. Esto es, de acuerdo con Hannah Arendt, sólo puede ser realizada en situaciones particulares en las que aquellos que no sufren se encuentran cara a cara con los que lo hacen (1990: 85) ${ }^{7}$. En tanto en cuanto se centra en individuos, por tanto, y no en realidades estructurales, el humanitarismo no puede por si mismo avanzar políticas de equidad. Y quizás más importante, en su versión actual y con sus formas institucionales, el humanitarismo de hecho mantiene la desigualdad dado que distingue entre dos poblaciones: los que pueden sentir y actuar por su compasión, y aquellos que serán sujetos (objetos) de esa compasión. Los que tienen el poder de proteger y los que necesitan protección.

Si queremos de verdad detener las cantidades crecientes de muertos en el umbral del primer mundo, tenemos que trabajar por la justicia con los migrantes, y no intentar sustituirla con caridad. El trabajo político para alcanzar esto debe ser un acto compartido, que implica repensar lo que la acción política y la justicia significan para todo el mundo — no sólo para aquellos supuestamente merecedores de ayuda o cuidado, o aquellos que quieren migrar. Todos debemos repensar cómo sería un mundo justo y equitativo, porque a todos nos afectaría. Hay ya movimientos en esta dirección: los que reivindican derechos humanos para todos, incluyendo el derecho a la movilidad. Estas son un conjunto de ideas poderosas e importantes, aunque aún sean los estados los que garanticen esos derechos humanos y aún se basen en teorías del individualismo y la soberanía. Hay otras estrategias más radicales para conseguir la justicia y la equidad, como la cruzada para la apertura de las fronteras, basada en la idea de la lucha por los bienes comunes. Esta idea va más allá de conceptos como estado, ciudadanía, y propiedad privada para orientarse hacia la idea de derechos comunes, lo cuales, más que centrarse en el derecho a excluir — como sucede hoy con las fronteras - se basan en el derecho a no ser excluido (Anderson, Sharma y Wright 2011). En esta visión de futuro eliminamos conceptos como "migrante" y "refugiado", o in-

\footnotetext{
${ }^{7}$ Arendt argumenta que Jesucristo es la excepción a esta regla, tal y como Fyodor Dostoevski lo representó. El signo de la divinidad de Jesús era su capacidad de tener compasión por todos los hombres en su singularidad, sin amontonarlos como una humanidad sufriente.

${ }^{8}$ Ver también Michel Agier and Francoise Gemenne, "Soyons réalistes: 10 raisons d'ouvrir les frontières", en L'Olbs Biblios. http://bibliobs.nouvelobs.com/idees/20150626.OBS1607/soyonsrealistes-10-raisons-d-ouvrir-les-frontieres.html?xtor=RSS-137
} 
cluso "ciudadano", dado que sus significados están enraizados en ideas excluyentes de pertenencia. Estos movimientos nos apremian para buscar nuevas formas de estar juntos a escala global, en base a la participación y el trabajo, el deber y la obligación, así como recursos comunes compartidos.

Argumentar en contra de las fronteras humanitarias no significa excluir la emoción frente a los muchos muertos; significa hacer hueco a sentimientos que encajen bien con diferentes proyectos para la equidad, con diversas visiones políticas. ¿Dónde está el lugar para el duelo que vaya más allá del estado de excepción, más allá de sentimientos de pena por los inocentes, y que fructifique a partir de la indignación y la esperanza?

\section{BIBLIOGRAFÍA CITADA}

Anderson, Bridget, Nandita Sharma y Cynthia Wright. 2011. "Editorial: Why No Borders?» Refuge 26: 5-18.

Arendt, Hannah. 1951. Origins of Totalitarianism. Nueva York: Meridian Books.

Arendt, Hannah. 1990. On Revolution. Harmondsworth: Penguin Books.

Boltanski, Luc. 1999. Distant Suffering: Morality, Media and Politics. Cambridge: Cambridge University Press.

Fassin, Didier. 2005. "Compassion and Repression: The Moral Economy of Immigration Policies in France». Cultural Anthropology 20(3): 362-87.

Fassin, Didier. 2010. "Inequality of Lives, Hierarchies of Humanity: Moral Commitments and Ethical Dilemmas of Humanitarianism", en Ilana Feldman y Miriam Ticktin (eds.), In the Name of Humanity: The Government of Threat and Care: 238-55. Durham: Duke University Press.

Feldman, Ilana. 2011. "The Humanitarian Condition: Palestinian Refugees and the Politics of Living". Humanity: An International Journal of Human Rights, Humanitarianism and Development 3(2): 155-72.

Hathaway, James. 2008. "The Human Rights Quagmire of 'Human Trafficking'. Virginia Journal of International Law 49(1): 1-59

Malkki, Liisa. 1996. "Speechless Emisaries: Refugees, Humanitarianism, and Dehistoricization". Cultural Anthropology 11(3): 377-404.

Ticktin, Miriam. 2005. "Policing and Humanitarianism in France: Immigration and the Turn to Law as State of Exception". Interventions: A Journal of Postcolonial Studies 7(3): 347-68. 